\title{
ANÁLISE DO PROCESSO DE RECUPERAÇÃO ESTRUTURAL DA PONTE GETÚLIO VARGAS NA ILHA DE ITAMARACÁ
}

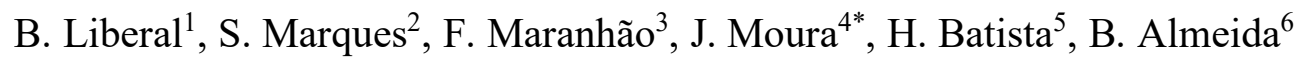 \\ *José Maria de Moura Júnior: jmmj@poli.br \\ ${ }^{1}$ Graduada em Engenharia Civil, Universidade de Pernambuco, Recife, Brasil \\ ${ }^{2}$ Mestre em Engenharia Civil, Universidade de Pernambuco, Recife, Brasil \\ ${ }^{3}$ Graduada em Engenharia Civil, Universidade de Pernambuco, Recife, Brasil \\ ${ }^{4}$ Mestrando em Engenharia Civil, Universidade de Pernambuco, Recife, Brasil \\ ${ }^{5}$ Graduada em Engenharia Civil, Universidade de Pernambuco, Recife, Brasil \\ ${ }^{6}$ Graduada em Engenharia Civil, Universidade de Pernambuco, Recife, Brasil
}

\begin{abstract}
RESUMO
A ponte Getúlio Vargas possui um histórico recorrente de manifestações patológicas e ausência de manutenções por parte do poder público e, por esse motivo, deve ser inspecionada periodicamente. Atualmente, a ponte encontra-se em processo de recuperação estrutural. Assim, objetivou-se acompanhar as etapas de execução do processo de recuperação estrutural e avaliar as medidas adotadas de acordo com o projeto executivo e a bibliografia existente. A metodologia baseou-se no acompanhamento da recuperação estrutural da ponte mediante visitas em campo, na qual foram realizadas inspeções visuais para registro do processo. Todos os elementos que foram recuperados tiveram sua condição de estabilidade melhorada, com exceção da laje do tabuleiro. Pode-se concluir que a estrutura da ponte não se comportou de forma monolítica ao longo dos anos. É possível afirmar que, com a finalização das obras, a durabilidade da Ponte Getúlio Vargas será estendida e, para que não volte a apresentar estados sofríveis de deterioração, é necessário que haja manutenções preventivas no futuro.
\end{abstract}

Palavras chave: Pontes; Recuperação Estrutural; Manifestações Patológicas; Obras de Arte.

\begin{abstract}
The Getúlio Vargas Bridge has a recurrent history of pathological manifestations and lack of maintenance by the government and, for this reason, it must be inspected periodically. Currently,
\end{abstract}


the bridge is in the process of structural recovery. Thus, the objective was to follow the stages of execution of the structural recovery process and evaluate the measures adopted in accordance with the executive project and the existing bibliography. The methodology was based on monitoring the structural recovery of the bridge through field visits, in which visual inspections were carried out to record the process. All the elements that were recovered had their stability condition improved, with the exception of the deck slab. It can be concluded that the bridge structure did not behave in a monolithic way over the years. It is possible to affirm that, with the completion of the works, the durability of the Getúlio Vargas Bridge will be extended and, so that it does not return to sufferable deterioration, it is necessary to have preventive maintenance in the future.

Keywords: Bridges; Structural recovery; Pathological manifestations; Special Engineering Structures.

\section{RESUMEN}

El Puente Getúlio Vargas tiene una historia recurrente de manifestaciones patológicas y falta de mantenimiento por parte del gobierno y, por ello, debe ser inspeccionada periódicamente. Actualmente, el puente se encuentra en proceso de recuperación estructural. Así, el objetivo fue seguir las etapas de ejecución del proceso de recuperación estructural y evaluar las medidas adoptadas de acuerdo con el proyecto ejecutivo y la bibliografía existente. La metodología se basó en el seguimiento de la recuperación estructural del puente mediante visitas de campo, en las que se realizaron inspecciones visuales para registrar el proceso. Todos los elementos recuperados mejoraron su estado de estabilidad, a excepción de la losa de tablero. Se puede concluir que la estructura del puente no se comportó de forma monolítica a lo largo de los años. Cabe afirmar que, con la finalización de las obras, se ampliará la durabilidad del Puente Getúlio Vargas y, para que no vuelva a sufrir estados de deterioro, es necesario contar con mantenimientos preventivos en el futuro.

Palabras clave: Pontes; Recuperação Estrutural; Manifestações Patológicas; Obras de Arte.

\section{INTRODUÇÃO}

O sistema construtivo de concreto armado passou a ser utilizado no Brasil na primeira década do século XX, inicialmente em obras de arte especiais (OAEs), como pontes e viadutos e, posteriormente, devido às mudanças políticas e ao crescimento da industrialização, passou também a ser utilizado em edificações (Santos, 2008).

Em relação ao processo construtivo, Mattje (2003) observa que, no passado, as estruturas de concreto armado eram projetadas de forma que a robustez das peças eram maiores, fazendo com que elas pudessem resistir durante anos sem comprometer sua integridade. Essa robustez se dava pelo superdimensionamento pelos seus altos índices de fator de segurança, a fim de evitar colapso progressivo ou danos maiores a estuturas. Porém, por mais robusta que seja a estrutura, ela ainda está sujeita a processos de deterioração, fazendo-se necessária a realização de manutenções preventivas ou corretivas nos elementos estruturais.

Por muito tempo, acreditou-se que as estruturas feitas desse material não sofriam deterioração com o tempo, mas Banduk (2008) aponta que essa ideia foi colocada à prova quando começaram a ser observados casos de estruturas com necessidade de reabilitação e recuperação estrutural, quando ainda não havia conhecimento de técnicas e materiais adequados para execução dessas operações. 
A maior parte das pontes que constituem a malha rodoviária federal brasileira é feita de concreto armado e possui idade superior a 30 anos, fator que torna escassas as informações acerca de seus projetos estruturais originais (Mendes et al., 2012). Essas estruturas, por serem antigas, foram executadas em desacordo com os padrões normativos vigentes e, por este motivo, é de suma importância considerar medidas mitigadoras dos efeitos negativos resultantes da deterioração nos elementos estruturais.

Com idade superior a 80 anos, a Ponte Getúlio Vargas foi construída em concreto armado e está localizada em região litorânea, com um fator de elevado risco de deterioração da estrutura. Como consequência, apresenta diversas manifestações patológicas e tornou-se motivo de preocupação para a população itamaracaense, tendo em vista que é a única estrutura que dá acesso ao município.

No ano de 2017, foi emitido um laudo técnico indicando que a estrutura havia atingido o estado limite de serviço (ELS), um indicador definido pela NBR 6118 (ABNT, 2014) relacionado à aparência e durabilidade da estrutura, atestando a necessidade imediata de serem realizadas intervenções a fïm de garantir a segurança e bem estar dos usuários.

Marques et al. (2018) observam que a Ponte Getúlio Vargas possui grande valor social e cultural e, por esse motivo, deve ser inspecionada de forma periódica por possuir um histórico recorrente de manifestações patológicas e ausência de manutenções por parte do poder público.

É visível a importância da recuperação estrutural da ponte, que é o único meio de acesso viário ao município de Ilha de Itamaracá, fazendo-se essencial para a população de mais de 25 mil habitantes (IBGE, 2020). Por este motivo, é necessário garantir soluções adequadas de reforço e recuperação estrutural para a ponte, com o objetivo de estender sua durabilidade. Assim, objetiva-se acompanhar as etapas de execução do processo de recuperação estrutural e avaliar as medidas adotadas de acordo com o projeto executivo e a bibliografia existente.

\section{REFERENCIAL TEÓRICO}

Sendo o concreto armado o principal sistema utilizado na construção civil, a falta de conhecimento em relação aos materiais utilizados, bem como a sua concepção, projeto, construção e manutenção podem resultar em grandes perdas diretas ou indiretas para a sociedade (Grochoski; Helene, 2008).

Aliada a essa ideia, Tomazelli (2019) assinala que, desde que sejam projetadas e construídas seguindo os padrões de qualidade presente nas normas técnicas e em concordância com o meio em que se encontram, as estruturas de concreto armado são capazes de se manter duráveis ao longo dos anos.

A NBR 6118 (ABNT, 2014) define a vida útil do concreto como o período em que as características das estruturas são mantidas, de forma a atender os requisitos determinados em projeto. No entanto, nem sempre é possível ter acesso aos projetos estruturais originais de construções antigas, fator que dificulta o processo de análise dos critérios adotados na construção. Branco et al. (2013) discorrem sobre o conceito de vida útil estrutural, que está associado a questões de segurança e utilização da estrutura e que depende essencialmente da evolução das ações atuantes sobre a estrutura e dos materiais utilizados. Ao se projetar uma estrutura para sua vida útil estrutural, garante-se que, dentro desse período, não haverá situações de colapso e nem comprometimento da estrutura.

A vida útil de uma estrutura está diretamente ligada com a durabilidade, que é definida pelo ACI Committee 201 (2001) como a capacidade que o concreto tem de suportar à ação de intempéries, ataque químico ou outros tipos de deterioração. 
Grochoski e Helene (2008) apontam que as estruturas de concreto armado têm potencial para apresentarem uma vida útil muito superior a 50 anos, porém estão se deteriorando de forma precoce mesmo antes de atingir essa idade.

O valor adotado para a vida útil em estruturas de concreto gira em torno de 50 anos, podendo ser maior no caso das pontes, chegando a 100 anos (Andrade, 1997). Ao atingir a idade prevista em projeto para sua vida útil, a probabilidade de ocorrência de colapso na estrutura aumenta, pois os valores característicos das ações que atuam sobre ela tendem a aumentar com o tempo (Branco; Paulo, 2012).

\subsection{Recuperação Estrutural}

O conhecimento dos mecanismos responsáveis pela formação das manifestações patológicas possibilitou estudar as técnicas adequadas para solucionar esses problemas. De acordo com Reis (2001), a recuperação de estruturas surgiu como um forte mercado da indústria da construção civil. A recuperação de estruturas atende a necessidade de reestabelecer as condições originais de estruturas danificadas, enquanto o reforço de estruturas promove a adequabilidade da capacidade resistente delas.

Existem diversos métodos de recuperação e reforço de estruturas. A escolha desses métodos e dos materiais a serem empregados na recuperação estrutural dependem do diagnóstico do problema, das características da região a ser recuperada e das exigências do funcionamento do elemento a ser recuperado (Helene, 1992).

Os critérios de seleção para a técnica a ser adotada nos reparos se dão por diversos fatores, sendo eles: a característica dos danos, a urgência do reparo, a acessibilidade da área a ser reparada, o material a ser utilizado, a confiabilidade na empresa que irá realizar o reparo e os aspectos econômicos (Aguado et al., 2003).

\section{ESTUDO DE CASO}

Para o desenvolvimento do trabalho, o objeto de estudo foi a Ponte Getúlio Vargas, localizada no estado de Pernambuco. No período de fevereiro a abril do ano de 2021, foram realizadas visitas em campo para acompanhar seu processo de recuperação estrutural.

Além da utilização das normas técnicas, foi realizada uma pesquisa bibliográfica de modo a reunir estudos desenvolvidos anteriormente na Ponte Getúlio Vargas. Nesta seção, serão apresentadas as características da área de estudo, bem como seu contexto histórico e as manutenções anteriormente realizadas na estrutura.

\subsection{Contexto histórico}

A ponte foi inaugurada no ano de 1939 sobre o Canal de Santa Cruz, sob o contexto da construção de uma Penitenciária Agrícola na Ilha de Itamaracá. Mota (1985) aponta que a construção da obra de arte marcou uma nova era de progresso para Itamaracá, facilitando a locomoção de seus habitantes, que não compreendiam a ilha isolada do resto do continente. Apesar de ter melhorado completamente o contexto da região, também havia algumas dificuldades enfrentadas em relação à largura da ponte, que não permitia o tráfego de dois veículos em sentidos contrários.

Construída pela Secretaria de Viação de Obras Públicas, sob a responsabilidade do engenheiro Manuel César de Morais Rêgo, a ponte Getúlio Vargas, com apenas 5,50m de largura, quarenta e cinco anos depois de inaugurada, acha-se obsoleta para o tráfego de veículos pesados, ônibus e caminhões, principalmente. Com essa largura, não permite a passagem de dois ônibus, em sentido contrário, e qualquer movimento maior de automóveis. Nos fins de semana, por exemplo, causa 
incríveis engarrafamentos, com intermináveis filas de carros entre Itapissuma e Itamaracá. (Mota, 1985, p.70)

\subsection{Caracterização da área de estudo}

A Ponte Getúlio Vargas, popularmente conhecida como "Ponte de Itamaracá", está inserida na Região Metropolitana do Recife, no litoral norte do estado, a cerca de $50 \mathrm{~km}$ da capital. Foi inaugurada no ano de 1939 sobre o Canal Santa Cruz, sendo a única estrutura responsável por ligar os municípios de Itapissuma e Ilha de Itamaracá.

A Ponte Getúlio Vargas possui 19 vãos e um comprimento total de 372,38 metros. Os vãos centrais da estrutura têm, em média, cerca de 20 metros de comprimento, enquanto os vãos de extremidade são menores, com 16,40 metros. A estrutura original da ponte foi construída com as longarinas engastadas nos pilares, de modo que a estrutura é hiperestática.

\subsection{Histórico de manutenções e manifestações patológicas}

Em 1995, foram realizadas pelo Departamento de Estradas e Rodagem (DER) intervenções de reforço na ponte, atribuindo à estrutura um alargamento do tabuleiro, aumentando a largura da faixa de rolamento para 7,20 metros, com dois passeios medindo 1,15 metros cada (Fragoso; Vitório, 2016).

Na Figura 1, é possível observar a inclusão da estrutura anteriormente mencionada, sendo a estrutura antiga representada em vermelho e a estrutura ampliada em verde. Para a execução da ampliação da faixa de rolamento e inclusão dos passeios, foram executadas quatro longarinas em concreto protendido e vigas travessas para o apoio delas (Matos, 2017).

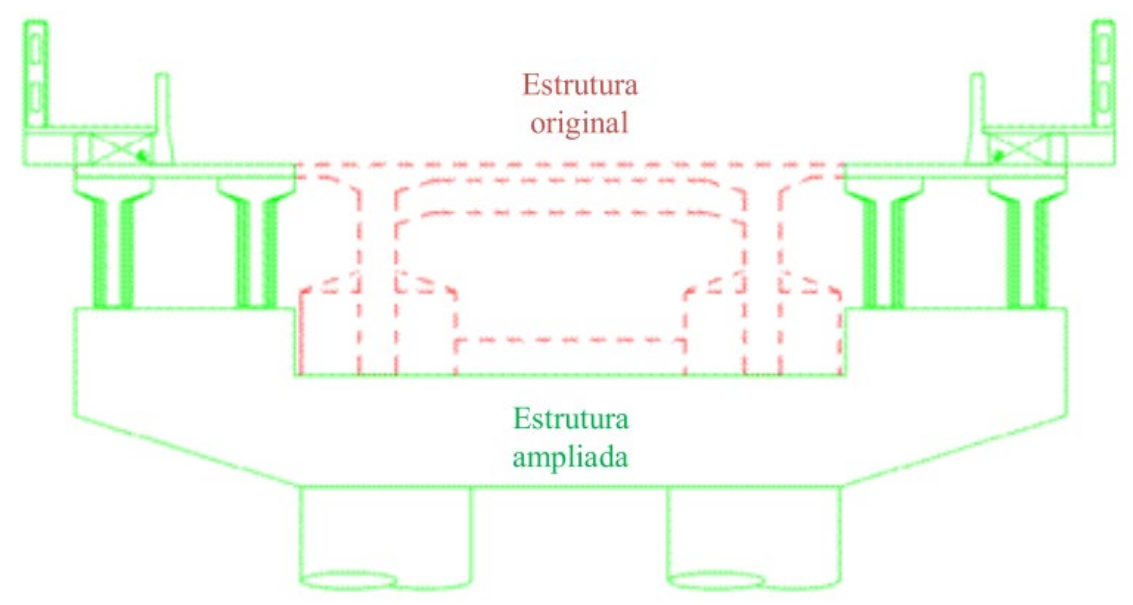

Fonte: Matos et al., 2018.

Figura 1. Ampliação da seção transversal da Ponte Getúlio Vargas

Com essa ampliação, a ponte passou a permitir a passagem de dois veículos em sentidos contrários, até então não sendo possível devido à pequena largura. Além disso, também foram incluídos elementos de segurança como as defensas para os veículos e os guarda-corpos para os pedestres.

Por ser antiga, não há informações disponíveis acerca do projeto estrutural original da ponte, o que torna difícil analisar se houve erros em fase de projeto. Visando avaliar o desempenho da ponte a nível estrutural, Marques et al. (2018) observaram por meio do software CSI Bridge que o dimensionamento original da ponte atendia satisfatoriamente às ações e carregamentos atuantes. A Figura 2 apresenta o análise dos deslocamentos verticais (eixo vertical) para o 
carregamento atuante em relação ao tabuleiro da ponte (eixo horizontal), tendo sido verificado que estes deslocamentos encontram-se dentro dos limites aceitáveis para a estrutura.

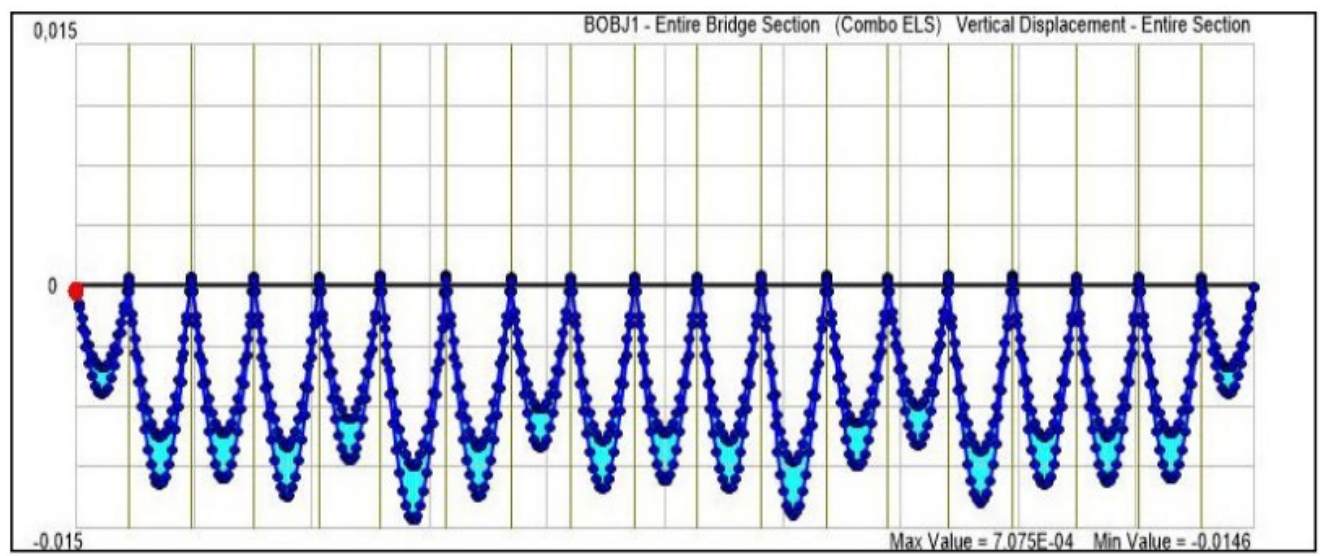

Fonte: Marques et al., 2018.

Figura 2. Deslocamentos verticais da estrutura original

Os deslocamentos foram obtidos utilizando a combinação frequente de ações especificadas na NBR 6118 (ABNT, 2014), para o estado limite de serviço (ELS).

Em um estudo realizado por Fragoso e Vitório (2016), foram mapeadas as manifestações patológicas encontradas na Ponte Getúlio Vargas por meio de inspeções visuais em campo, bem como suas possíveis causas. As informações obtidas estão apresentadas na Tabela 1.

Tabela 1. Manifestações patológicas encontradas na Ponte Getúlio Vargas e suas prováveis causas

\begin{tabular}{|c|c|c|}
\hline Elemento estrutural & Manifestações Patológicas & Principais causas \\
\hline Blocos de fundação & Incrustação biológica & Oscilação da maré \\
\hline Pilares & Incrustação biológica & $\begin{array}{c}\text { Oscilação da maré; penetração de } \\
\text { íns cloreto; alta porosidade do } \\
\text { concreto; cobrimento insuficiente } \\
\text { de armaduras }\end{array}$ \\
\hline Vigas travessas & $\begin{array}{c}\text { Corrosão de armaduras; fissuração; } \\
\text { destacamento do cobrimento; } \\
\text { manchas de oxidação }\end{array}$ & $\begin{array}{c}\text { Respingos de maré; penetração de } \\
\text { agentes agressivos; infiltrações } \\
\text { pela junta de dilatação; cobrimento } \\
\text { insuficiente; alta porosidade do } \\
\text { concreto }\end{array}$ \\
\hline Transversinas & $\begin{array}{c}\text { Mofo; bolor; eflorescência; corrosão } \\
\text { de armaduras }\end{array}$ & $\begin{array}{c}\text { Fissuras no pavimento. Infiltração } \\
\text { no tabuleiro; falhas no sistema de } \\
\text { drenagem }\end{array}$ \\
\hline Longarinas & $\begin{array}{c}\text { Corrosão de armaduras; e } \\
\text { florescência; mofo; bolor }\end{array}$ & $\begin{array}{c}\text { Infiltrações no tabuleiro; falhas no } \\
\text { sistema de drenagem }\end{array}$ \\
\hline Tabuleiro & Infiltrações; eflorescência; mofo; \\
bolor; corrosão de armaduras & $\begin{array}{c}\text { Fissuras no pavimento; } \\
\text { deformação devido à variação da } \\
\text { temperatura e cargas móveis; } \\
\text { entrada de umidade }\end{array}$ \\
\hline Juntas de dilatação & Desgaste e ausência dos lábios \\
poliméricos; infiltrações & $\begin{array}{c}\text { Deterioração por abrasão pelo } \\
\text { fluxo de carros; movimentação } \\
\text { estrutural pela variação térmica e } \\
\text { cargas móveis }\end{array}$ \\
\hline Passeios & Corrosão de armaduras; manchas de & Penetração de íons cloreto; \\
\hline
\end{tabular}




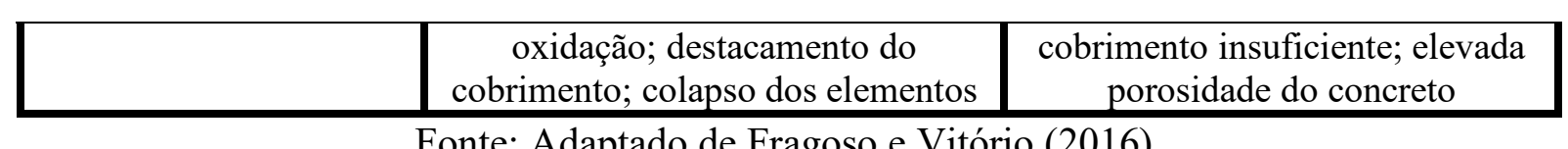

Fonte: Adaptado de Fragoso e Vitório (2016).

Os passeios e o guarda-corpo, além de apresentarem os problemas listados anteriormente, haviam atingido o estado limite último (ELU). Por esse motivo, foi necessário realizar a demolição total desses elementos, que passaram por um processo de reconstrução no ano de 2017. Com exceção dos passeios e guarda-corpo, não foram realizadas manutenções em outros elementos estruturais até o ano de 2020, desde a última ampliação.

\section{METODOLOGIA}

O estudo teve início em fevereiro de 2021, por meio de pesquisas na literatura existente sobre os aspectos que englobam este trabalho. Inicialmente, foi realizada uma visita à Ponte Getúlio Vargas acompanhada pelo responsável técnico do projeto de recuperação estrutural, em que foram registradas as fotografias que abordam as etapas de execução do projeto que serão apresentadas.

Por meio do responsável técnico, foi obtido um relatório técnico emitido no ano de 2017 sobre o diagnóstico da ponte àquela altura. Além disso, também foi obtido o projeto executivo de recuperação estrutural que estava sob responsabilidade do Departamento de Estradas e Rodagem (DER).

Em contato com o engenheiro responsável pela execução do projeto, foi possível obter os ensaios de resistência à compressão do concreto a ser utilizado nos elementos que foram recuperados até o momento de conclusão do trabalho, em abril de 2021, do primeiro ao quinto vão da ponte. Além disso, foram disponibilizadas várias imagens que serviram para a criação desse artigo (todas foram creditadas aos devidos autores).

Mediante visitas em campo, foram realizadas inspeções visuais para classificar os elementos estruturais da ponte de acordo com as recomendações presentes na norma DNIT 010 (DNIT, 2004), relativa à inspeção de pontes e viadutos de concreto armado e protendido.

\subsection{Ensaio de resistencia à compressão.}

Foram realizados ensaios de resistência à compressão no concreto aplicado nas estruturas a serem reforçadas, para garantir que o valor do $\boldsymbol{f}_{\boldsymbol{c} \boldsymbol{k}}$ estava de acordo com o valor previsto em projeto, que era de 50MPa. Para isso, foram coletadas amostras do concreto moldadas in loco, em corpos de prova cilíndricos de $10 \times 20 \mathrm{~cm}$, que foram rompidos nas idades de 7 e 28 dias.

A empresa de consultoria contratada pela empresa executora do projeto para realizar os ensaios utilizou como equipamento a Prensa Hidráulica Contenco. Neste ensaio, foram indicadas as cargas máximas de ruptura do corpo de prova em toneladas, bem como a resistência característica do concreto em MPa.

\subsection{Recuperação estrutural}

O projeto executivo, de responsabilidade do DER, foi elaborado para toda a extensão da ponte, exceto passeios e guarda-corpo, que já haviam sido recuperados anteriormente. Para todos os elementos estruturais, foi especificado um concreto com $\boldsymbol{f}_{\boldsymbol{c} \boldsymbol{k}}$ igual a $50 \mathrm{MPa}$. Inicialmente, foi realizado o isolamento com tapumes laterais por toda extensão da ponte e construídos andaimes suspensos. A locação dos andaimes pode ser observada nas Figuras 3 (a) e (b). 
a)

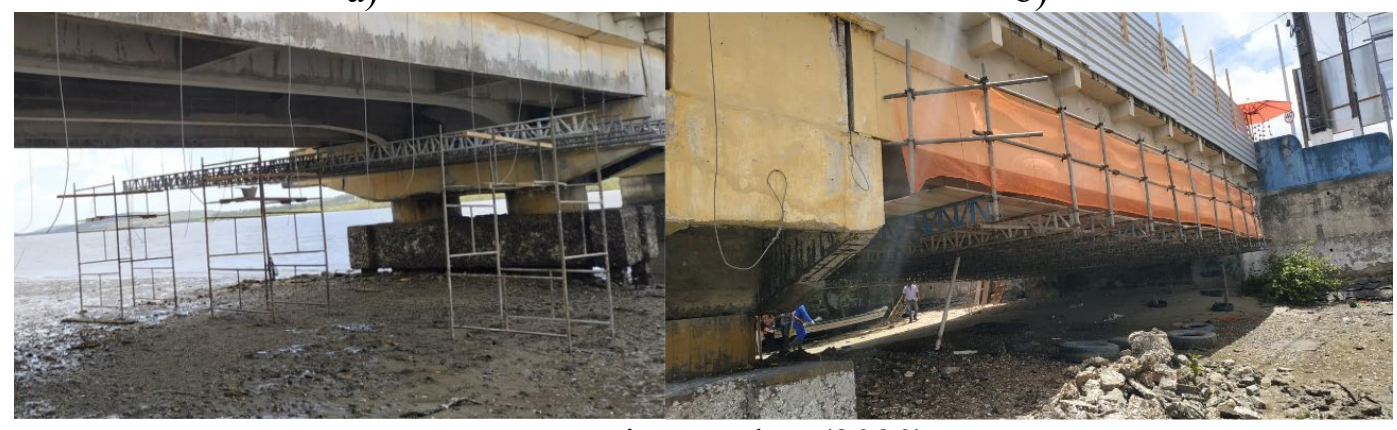

Fonte: Tiago Cobra (2020) b)

b) Andaimes suspensos

Também foi necessária a utilização de uma balsa para o preparo do concreto projetado a ser utilizado nos elementos estruturais, bem como a utilização de uma embarcação de apoio. A balsa e a embarcação podem ser observadas nas Figura 4 (a) e (b).

a)

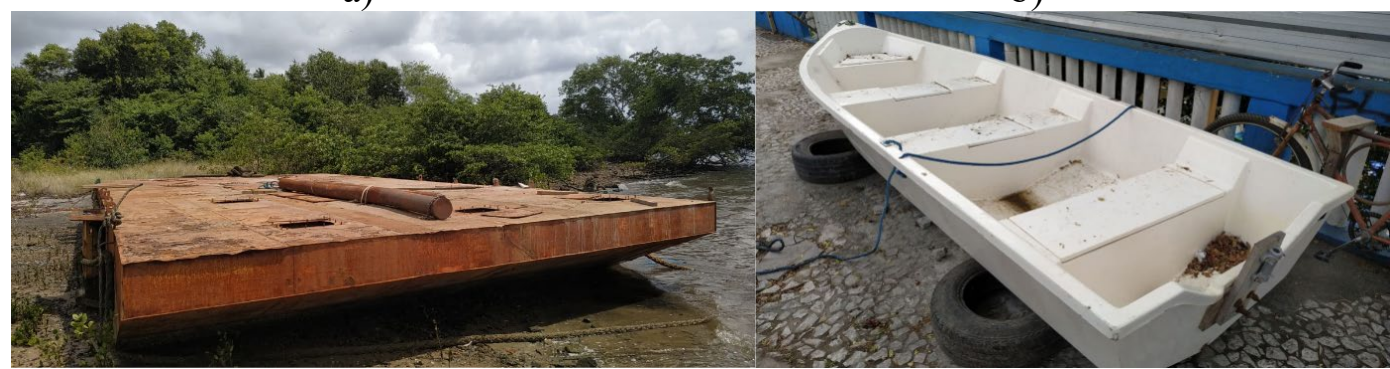

Fonte: Tiago Cobra (2020)

Figura 4. a) Balsa b) Embarcação de apoio

\section{RESULTADOS}

\subsection{Avaliação dos elementos estruturais.}

Com base nas visitas de inspeção realizadas acompanhadas pelo responsável técnico do projeto de recuperação estrutural, em conjunto com os estudos anteriormente realizados na ponte, chegou-se às análises apresentadas no apresentadas na Tabela 2.

Tabela 2. Avaliação do estado da ponte antes e após o processo de recuperação estrutural.

\begin{tabular}{|c|c|c|c|c|}
\hline Elemento estrutural & $\begin{array}{c}\text { Nota antes do } \\
\text { processo de } \\
\text { recuperação }\end{array}$ & $\begin{array}{c}\text { Condição de } \\
\text { estabilidade } \\
\text { inicial }\end{array}$ & $\begin{array}{c}\text { Nota após o } \\
\text { processo de } \\
\text { recuperação }\end{array}$ & $\begin{array}{c}\text { Condição de } \\
\text { estabilidade } \\
\text { final }\end{array}$ \\
\hline Blocos de fundação & 2 & Sofrível & 5 & Boa \\
\hline Pilares & 2 & Sofrível & 5 & Boa \\
\hline Transversinas & 2 & Sofrível & 5 & Boa \\
\hline Longarinas centrais & 2 & Sofrível & 5 & Boa \\
\hline Longarinas de periferia & 4 & Boa & 5 & Boa \\
\hline
\end{tabular}

Todos os elementos que foram recuperados tiveram sua condição de estabilidade melhorada, com exceção da laje do tabuleiro, tendo em vista que as medidas tomadas interferiram no estado do elemento apenas de maneira superficial. 
Os blocos de fundação, pilares, transversinas e longarinas centrais apresentavam as situações mais críticas, podendo ser justificado por serem elementos estruturais originais, que não haviam passado por manutenções.

Os aparelhos de apoio não puderam ser avaliados, pois até o momento de conclusão do estudo ainda não haviam sido recuperados. Espera-se, baseado nas medidas adotadas em projeto que foram apresentadas anteriormente, que a condição de estabilidade final seja classificada como boa, pois os aparelhos de apoio serão totalmente renovados.

Os passeios e guarda-corpo haviam sido recuperados no ano de 2017 e não apresentaram sinais de comprometimento estrutural no momento da análise. Era esperado que estivessem em melhores condições que os demais elementos da ponte, que não haviam passado por manutenções anteriormente.

\subsection{Ensaios de resistência a compressão.}

Os valores de resistência característica obtidos aos 28 dias foram organizados no gráfico presente na Figura 5. Pode-se observar que, das dezoito amostras rompidas com idade de 28 dias, apenas uma não alcançou o valor de $\boldsymbol{f}_{\boldsymbol{c} \boldsymbol{k}}$ especificado em projeto, que foi de $50 \mathrm{MPa}$.

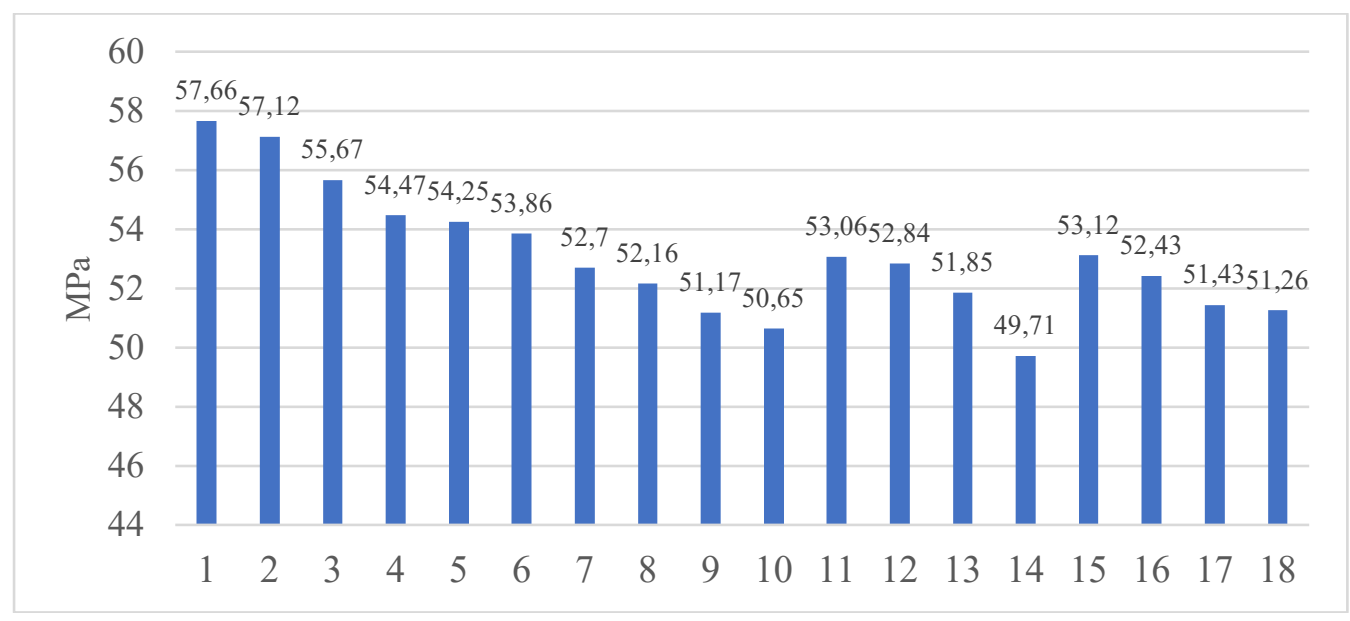

Figura 5. Valores característicos de resistência dos corpos de prova aos 28 dias.

O corpo de prova que apresentou $\boldsymbol{f}_{\boldsymbol{c} \boldsymbol{k}}$ inferior ao esperado pertence ao terceiro vão da viga, sentido Itapissuma-Itamaracá. $\mathrm{O}$ valor foi apenas $0,58 \%$ menor do que o valor especificado em projeto, podendo ser desconsiderado.

\subsection{Recuperação estrutural.}

Nesta seção, serão apresentados os registros fotográficos das etapas de recuperação que foram acompanhadas. Estão descritos os procedimentos realizados nos blocos de fundação, vigas, pilares, laje e as medidas previstas para a troca dos aparelhos de apoio, que não puderam ser acompanhados.

\subsubsection{Blocos de Fundação}

Inicialmente, foi realizada a limpeza do material incrustado nos blocos de fundação de forma manual. Após a retirada da bioincrustação marinha, foi realizada uma escarificação mecânica nos blocos, com profundidade de três a seis centímetros, indicada na Figura 6 (a). 
a)

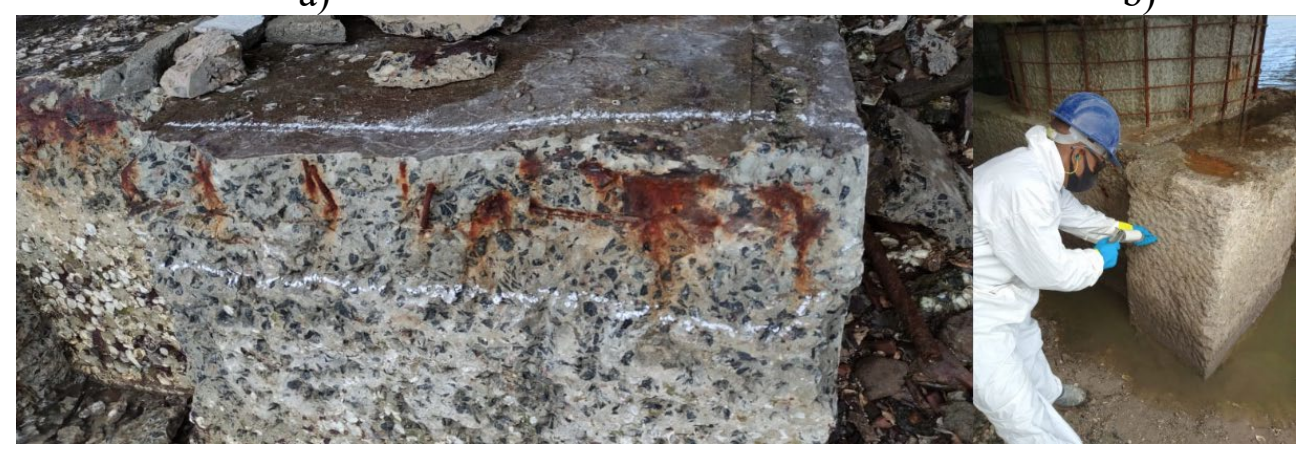

Fonte: Tiago Cobra (2020)

Figura 6. a) Bloco de fundação escarificado b) Tratamento de fissuras e trincas

Após a limpeza da superfície, foi realizado um tratamento de trincas e fissuras por injeção de resina epóxi, que pode ser observado na Figura 6 (b). Em seguida, os blocos de fundação foram encamisados (Figura 7 (a)) com as armaduras de reforço especificadas no projeto executivo, uma malha nervurada do tipo Telcon Q92, que têm como objetivo dar aderência ao graute a ser jateado e evitar possíveis fissuras (Figura 7 (b)).

a)

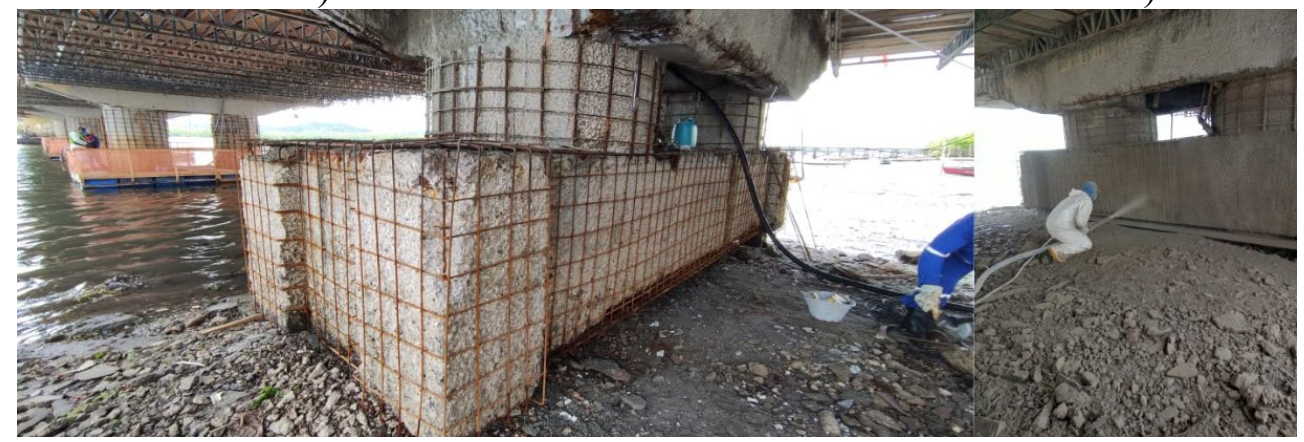

Fonte: Tiago Cobra (2020)

Figura 7. a) Armadura de reforço no bloco de fundação b) Graute jateado

\subsubsection{Vigas}

Para a execução da recuperação nas vigas, inicialmente foi realizado um preparo da superfície a ser tratada, que teve início com a realização de inspeção à percussão em toda a estrutura. Em seguida, foram realizadas as etapas relativas ao preparo do substrato, com a escarificação mecânica com profundidade de três a seis centímetros, como indicado nas Figuras 8 (a) e (b).

a)

b)

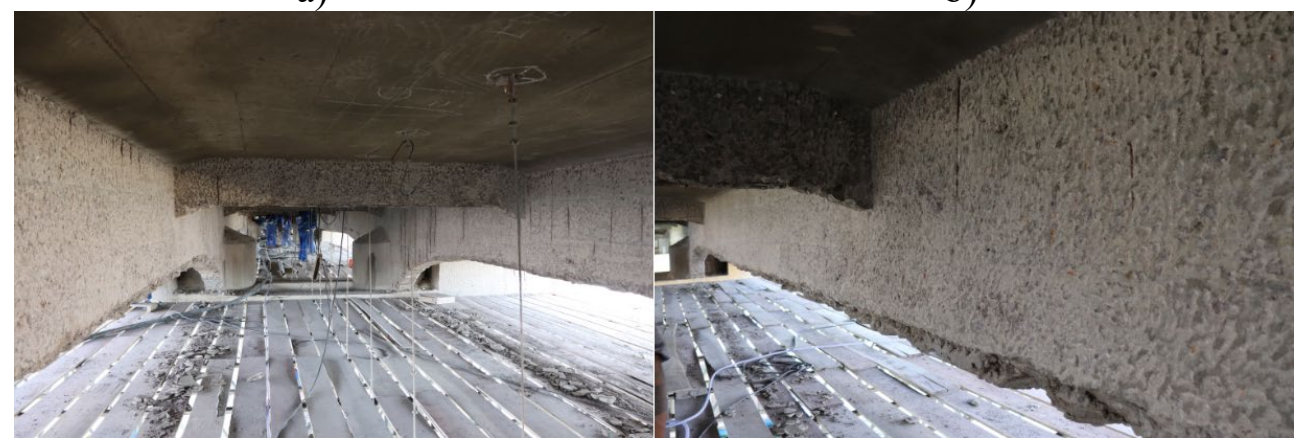

Figura 8. a) Vigas principais e transversina escarificada b) Viga principal escarificada 
Por fim, foi feita uma limpeza na superfície com remoção de resíduos por meio de jateamento de água e areia. Para o tratamento de trincas e fissuras, foram realizados furos de oito a doze centímetros de profundidade (Figura 9 (a)), onde foram introduzidos tubos plásticos, conforme Figura 9 (b) com pontas salientes.

a)

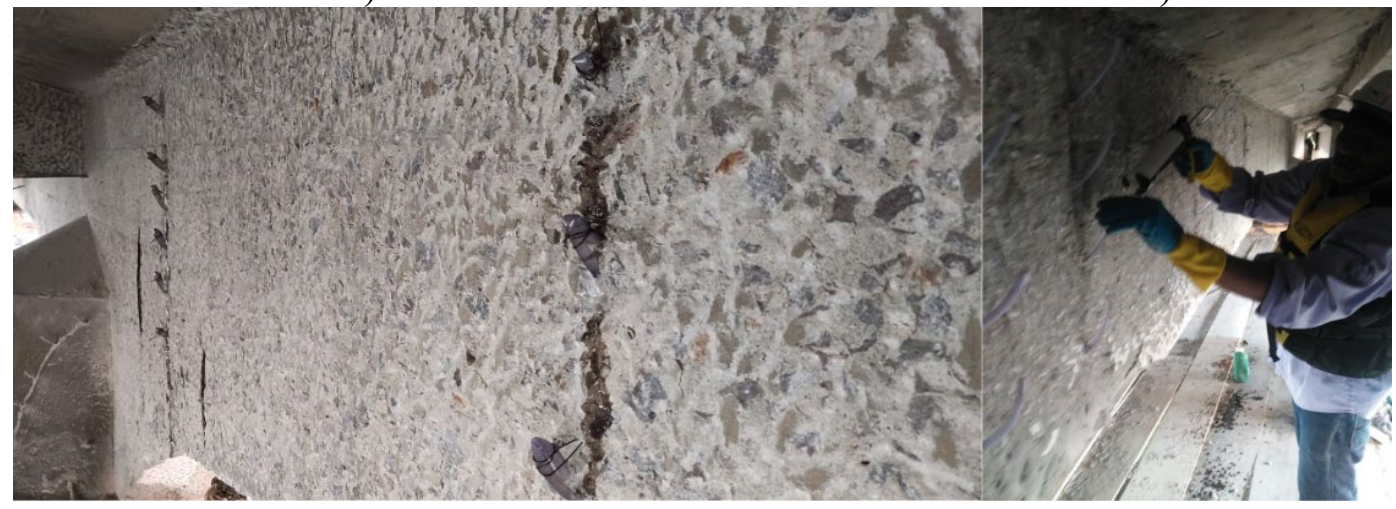

Fonte: Tiago Cobra (2021)

Figura 9. a) Viga principal com furos e tubos plásticos b) Injeção de tubos

Os tubos plásticos foram espaçados verticalmente e fixados com material selante. A resina epóxi foi injetada para o tratamento de trincas e fissuras, sendo aplicada em um tubo de cada vez, iniciando pelo inferior. Após a finalização, as pontas dos tubos foram cortadas e o material excedente foi lixado e a superfície foi limpa.

Após a limpeza da superfície do concreto e das armaduras, foi realizado um tratamento prévio nas armaduras expostas por meio de pintura de proteção específica, conforme Figura 10 (a).

a)

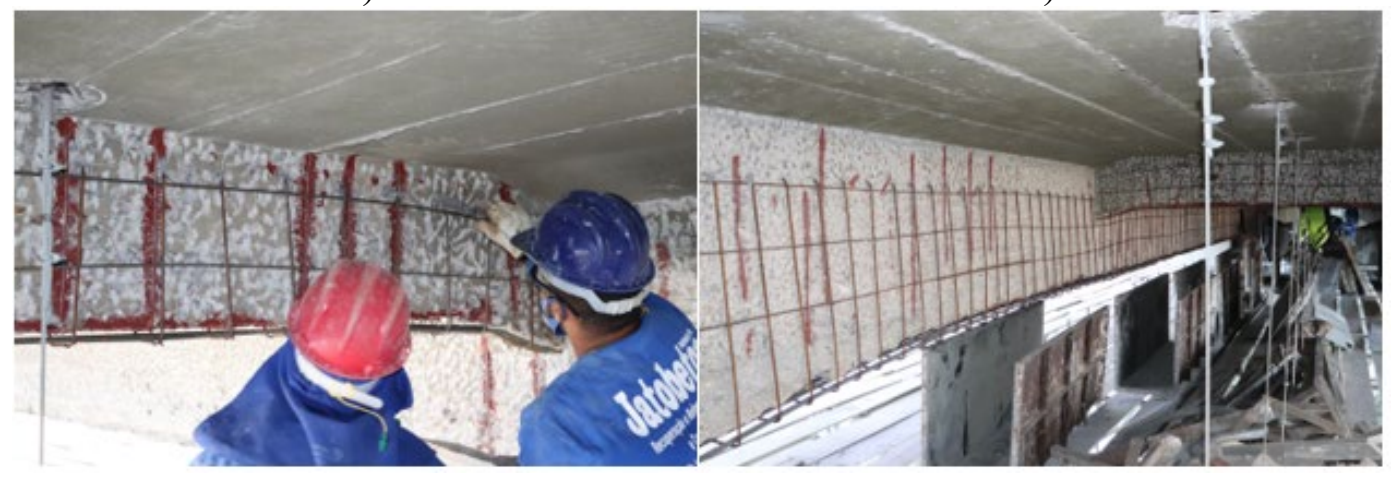

Figura 10. a) Aplicação de resina no encontro das armaduras b) Viga principal armada

A proteção é composta por um primer rico em cromato de zinco, que age como elemento passivador e neutraliza as reações eletroquímicas que possam ocorrer nas armaduras. Também é possível observar na Figura 10 (b) as formas a serem utilizadas nas vigas para aplicação do graute. O detalhamento genérico dessas formas está descrito na Figura 11, em verde. 


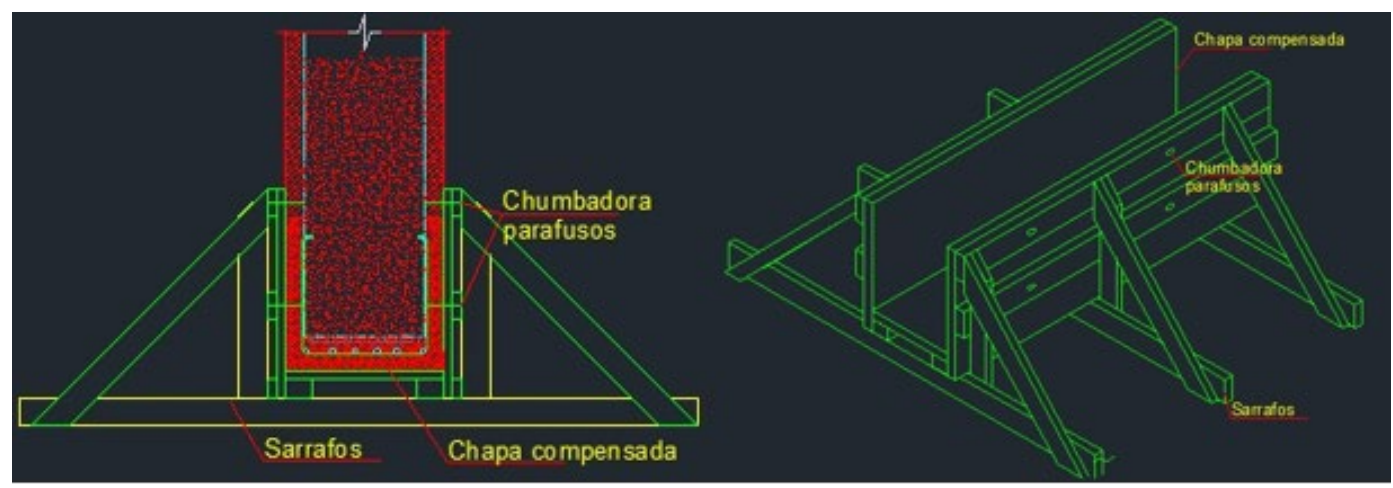

Figura 11. Detalhamento genérico das formas

As formas utilizadas foram feitas em chapa compensada e são presas por sarrafos, para garantir que a forma fique imobilizada e que não haja vazamento do graute cimentício a ser aplicado. $\mathrm{O}$ graute utilizado na parte inferior das vigas foi do tipo convencional, que é mais fluido, indicado na Figura 11 por uma cor avermelhada mais intensa. Esse tipo de graute dispensa o uso de vibradores devido à sua plasticidade e garante que não haverá ninhos de concretagem entre as armaduras.

Nas demais áreas da viga, foi aplicado graute do tipo tixotrópico, que possui menor fluidez e excelente aderência em bases verticais. Por esse motivo, não foi necessário utilizar formas nas áreas em que esse tipo de graute foi aplicado.

\subsubsection{Pilares}

Inicialmente, foi realizada limpeza de forma manual das superfícies dos pilares em que havia bioincrustação marinha. Após o procedimento de limpeza, os pilares foram escarificados e envolvidos com uma malha nervurada do tipo Telcon Q92, que garante melhor ancoragem e controla possíveis fissurações no concreto.

A malha foi incorporada ao pilar por meio de perfuração no concreto existente e injeção de resina epoxídica para garantir a fixação das barras. Os furos para recebimento das armaduras possuem profundidade de $20 \mathrm{~cm}$. A malha nervurada pode ser observada na Figura 12 (a), bem como o jateamento do concreto aplicado ao redor dos pilares.

a)

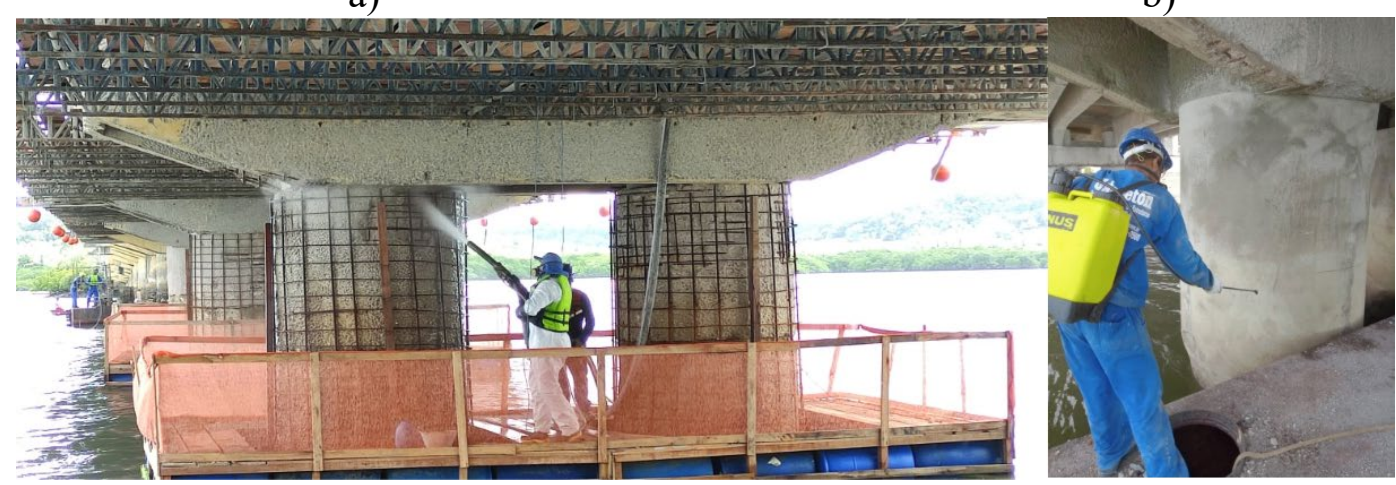

Fonte: Tiago Cobra (2021)

Figura 12. a) Projeção de concreto nos pilares b) Pintura inibidora de corrosão no pilar

O concreto foi projetado nos pilares até que fosse alcançado o cobrimento de cinco centímetros especificado em projeto. Após a finalização do reforço no pilar, foi aplicada uma pintura inibidora de corrosão, indicada na Figura 12 (b). 
Para o jateamento, foi aproximada ao pilar uma estrutura flutuante indicada na Figura 13 (a), composta por um equipamento de mistura do graute que conduz o material a um mangote com um bico projetor. O material então é aplicado sob pressão, não necessitando de compactação devido à alta velocidade com que é aplicado. A Figura 13 (b) mostra a vista superior do jateamento de graute nos pilares.

a)

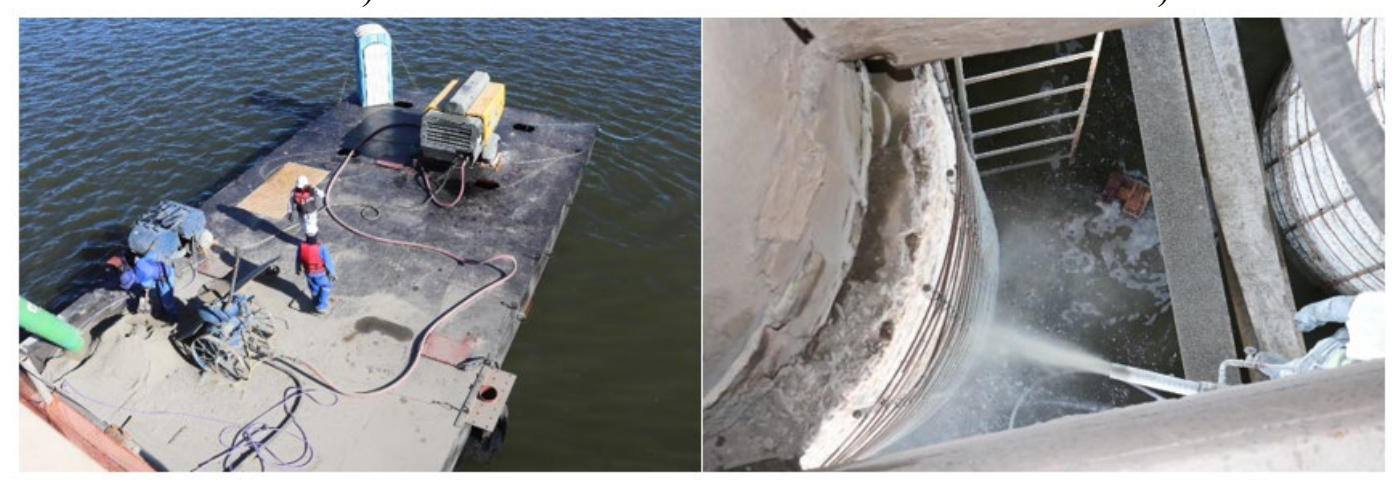

Figura 13. a) Balsa para preparo do graute b) Vista superior do jateamento de graute nos pilares

\subsubsection{Lajes}

As lajes apresentavam corrosão em alguns pontos em que as armaduras estavam expostas, mas apesar das corrosões e das manchas superficiais causadas pelas infiltrações, ocasionando mofo e bolor, as lajes não apresentavam necessidade de grandes reparos.

A solução adotada consistiu apenas em aplicar o mesmo tratamento dado à armadura das vigas, em que foi aplicada uma camada de proteção composta por um primer rico em cromato de zinco, neutralizando as reações eletroquímicas que possam ocorrer nas armaduras. As armaduras expostas e a aplicação do tratamento podem ser observadas nas Figura 14 (a) e (b).

a)

b)

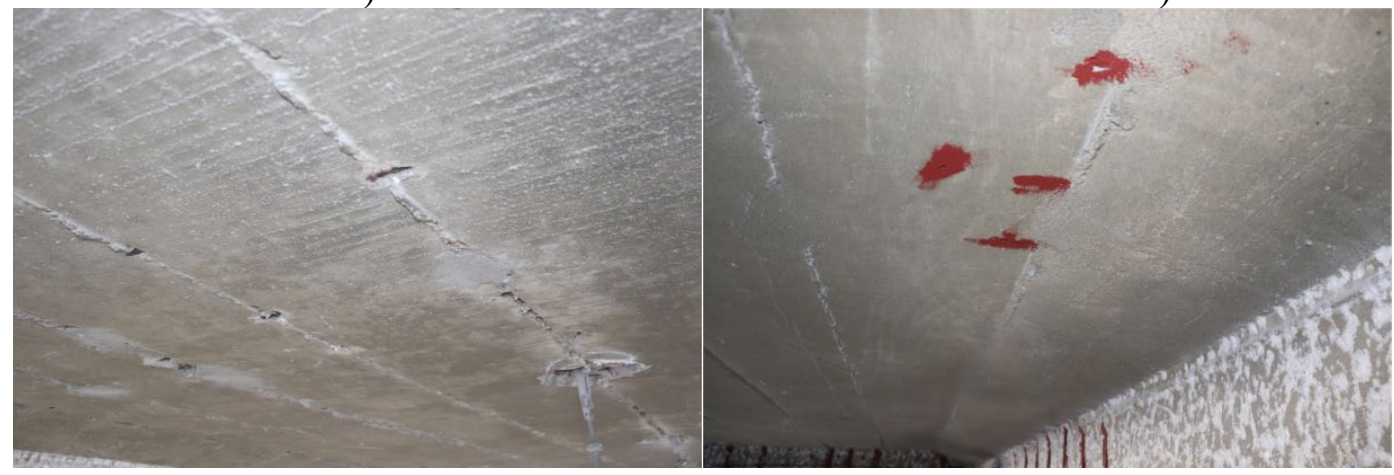

Figura 14. a) Corrosão nas armaduras da laje b) Tratamento aplicado à armadura da laje

\section{CONCLUSÕES}

Com este estudo, pode-se constatar que a estrutura da ponte não se comportou de forma monolítica ao longo dos anos. A análise individual dos elementos estruturais possibilitou verificar que cada um deles está em uma fase diferente do processo de deterioração, mesmo que estejam inseridos no mesmo ambiente.

O estado de alguns pontos da estrutura tornava necessária a intervenção estrutural por ter se tornado desconfortável para os usuários, ao atingir o ELS. Não há como afirmar para quanto tempo de vida útil a ponte foi projetada, tendo em vista que não há registros de seu projeto 
estrutural original. Da mesma forma, não há como responsabilizar erros conceituais no projeto pelo atual estado da ponte.

Os ensaios realizados no graute utilizado nas vigas do primeiro ao quinto vão mostraram-se satisfatórios. Os corpos de prova apresentaram resistência igual ou superior à especificada em projeto, de 50MPa, que é o valor de resistência indicado para ambientes agressivos.

Como não foram realizados ensaios de resistência à compressão no concreto da estrutura original, não há como afirmar que o concreto utilizado no reforço foi inferior a $20 \%$ do concreto existente, como indicado na norma DNIT 084 (DNIT, 2006). Uma vez que a metodologia utilizada para avaliar o estado dos elementos estruturais baseia-se em inspeções visuais, é necessário que haja acompanhamento de como a estrutura irá se comportar em longo prazo.

As medidas de recuperação e reforço executadas de acordo com o projeto executivo se mostraram adequadas, baseadas na literatura técnica existente. É possível afirmar que, com a conclusão das obras, a durabilidade da Ponte Getúlio Vargas será estendida e, para que não volte a apresentar estados sofríveis de deterioração, é necessário que haja manutenções preventivas no futuro. Dessa forma, será possível garantir aos usuários a segurança estrutural adequada da ponte, bem como a preservação dela, que possui grande importância histórica e econômica.

\section{REFERÊNCIAS}

ACI Committee 201, 2001, "Guide to Durable Concrete (ACI 201.2R-01)," American Concrete Institute, Farmington, Hills, Mich. 41p.

AGUADO, A. et al. (2003), Orientación para la selección de la intervención. In: HELENE, P.; PEREIRA, F. "Manual de rehabilitación de estructuras de hormigón: reparación, refuerzo y protección”, São Paulo, Cyted, cap. 3, pp. 1-45.

Andrade, J. J. de O. (1997), “Durabilidade Das Estruturas De Concreto Armado: Análise das manifestações patológicas nas estruturas no estado de Pernambuco", Dissertação, Universidade Federal do Rio Grande do Sul, p. 151.

Assis, L. F. (2001), “A difusão do turismo de segunda residência das paisagens isulares: um estudo sobre o litoral Sul da Ilha de Itamaracá - PE”, Dissertação, Universidade Federal de Pernambuco, p. 183.

Associação Brasileira de Normas Técnicas. (2014). NBR 6118: Projeto de Estruturas de Concreto - Procedimento. Rio de Janeiro.

Banduk, R. C. (2008), Ensino das técnicas de recuperação. Concreto \& construções. 35(49):4952.

Branco, F.; Paulo, P.; Garrido, M. (2013), Vida útil en la construcción civil. Boletim Técnico Vida Útil na Construção Civil, Mérida, n. 4, p. 20.

Branco, F.; Paulo, P. V. (2012), O projecto de pontes para vidas superiores a 100 anos. Revista ALCONPAT. 2(1):1-9. https://doi.org/10.21041/ra.v2i1.20.

Departamento Nacional de Infraestrutura de Transportes. (2004). DNIT 010: Inspeções em pontes e viadutos de concreto armado e protendido - Procedimento. Rio de Janeiro. 
Departamento Nacional de Infraestrutura de Transportes. (2006). DNIT 084: Tratamento da corrosão - Especificação de serviço. Rio de Janeiro.

Fragoso, V. S.; Vitório, J. A. P. (2016), Análise das Atuais Condições Funcionais e Estruturais da Ponte Getúlio Vargas, na Rodovia PE-35. Revista de Engenharia e Pesquisa Aplicada, 3(1). https://doi.org/10.25286/repa.v3i1.539.

Grochoski, M.; Helene, P. Sistemas de reparo para estruturas de concreto com corrosão de armaduras. Boletim Técnico da Escola Politécnica da USP, Departamento de Engenharia de Construção Civil, BT/PCC/5, São Paulo, p. 21, 2008.

Helene, P. (1992), "Manual para reparo, reforço e proteção de estruturas de concreto”. Pini, São Paulo, Brasil, p. 216.

IBGE, "Estimativas da população residente no Brasil e Unidades da Federação com data de referência em $1^{\circ}$ de Julho de 2020". Disponível em: $<$ https://ftp.ibge.gov.br/Estimativas_de_Populacao/Estimativas_2020/POP2020_20210204.pdf $>$. Acesso em: 10 mar. 2021.

Marques, S. J. P. J. et al. (2018). "Recuperação Estrutural da Ponte Getúlio Vargas - PE" in: Congresso Brasileiro de Pontes e Estruturas, v. X, p. 10.

Matos, C. B. M. et al. (2018). “Avaliação da degradação dos passeios da ponte Getúlio Vargas$P E$ ” in: Encontro Luso-Brasileiro de Degradação em Estruturas de Concreto Armado, São Carlos: v. 3, p. 11 .

Matos, C. B. M. (2017), "Ponte de Itamaracá: Patologias e recuperação estrutural”, Trabalho de Conclusão de Curso, Escola Politécnica da Universidade de Pernambuco, p. 94.

Mattje, A. (2003), “Contribuição ao Estudo da Durabilidade de Pontes em Concreto do Sistema Rodoviário de Santa Catarina (Litoral e Vale do Itajaí)", Dissertação, Universidade Federal de Santa Catarina, p. 188.

Mendes, P. T. C.; Moreira, M. L. T.; Pimenta, P. M. (2012), Reinforced concrete bridges: effects due to corrosion and concrete young modulus variation. Revista IBRACON de Estruturas $e$ Materiais. 5(3):405-419. https://doi.org/10.1590/S1983-41952012000300008.

Mota, A. da. (1985), "Itamaracá: análise socio-econômica da histórica ilha pernambucana". Companhia Editora de Pernambuco, Recife, Brasil, p. 104.

Reis, L. S. N. (2001), "Sobre a recuperação e reforço de estruturas de concreto armado", Dissertação, Escola de Engenharia da Universidade Federal de Minas Gerais, p. 112.

Santos, R. E. dos. (2008), “A armação do concreto no Brasil: história da difusão da tecnologia do concreto armado", Tese, Universidade Federal de Minas Gerais, p. 338.

Tomazeli, A. (2019), "Estruturas paralisadas de concreto armado de edifícios: inspeção, análise e aceitação". Editora Leud, São Paulo, Brasil, p. 248. 